\title{
O DESENVOLVIMENTO DE PRODUTOS PARA ÁREA MÉDICA NA UNIVERSIDADE POR MEIO DA INOVAÇÃO ABERTA
}

João Gabriel Alves Ribeiro Rosa (joaogabrieldesigner@gmail.com) - Escola de Engenharia, Universidade Federal de Minas Gerais

Eduardo Romeiro Filho (romeiro@dep.ufmg.br) - Escola de Engenharia, Universidade Federal de Minas Gerais

\section{RESUMO}

A área de atenção à saúde é notadamente complexa em termos de desenvolvimento de produtos, tendo em vista uma abordagem necessariamente multidisciplinar, com muitas vezes longos períodos para a implementação de inovações, devido também à rigidez da normatização relacionada à utilização de equipamentos de saúde. Partindo deste cenário, este artigo tem como objetivo apresentar uma experiência de desenvolvimento de produtos da área de saúde (um aparelho auditivo) no contexto acadêmico, centrado no trabalho compartilhado por duas Universidades, uma no Brasil e outra no Reino Unido. Este projeto conta com o apoio financeiro da FAPEMIG - Fundação de Amparo à Pesquisa de Minas Gerais e se desenvolve por meio de práticas de inovação de fonte aberta em conjunto com o fablab de uma universidade corporativa ligada a uma empresa metal mecânica privada. A pesquisa busca demonstrar a viabilidade da inovação a partir do trabalho cooperativo entre pesquisadores, voltada para o desenvolvimento de soluções adequadas (mas não restritas) à população de baixo poder aquisitivo. São ressaltados aspectos ligados à participação de diversos grupos (professores, alunos de graduação e pós-graduação, pesquisadores, pessoal de empresa etc.) no processo de desenvolvimento e como este processo pode dar origem à inovação a partir da participação ativa da academia.

Palavras-chave: Open innovation; Aparelho auditivo; Produtos para a Saúde

Área: Gestão do Processo de Desenvolvimento de Produtos

\section{INTRODUÇÃO}

A inovação é tema central em muitas discussões nos dias de hoje. Fator decisivo para a sobrevivência das empresas, principalmente em tempos de recessão e no momento histórico onde o mercado está saturado. Para continuar a serem competitivas, as empresas precisam inovar e se adaptar às mudanças mercadológicas (ROSSI, 2009). Inovar, entretanto, não é fácil. Além de se desenvolver novas tecnologias e produtos, no campo industrial, é preciso entender a conjuntura mercadológica e aplicação para ser bem sucedida. A inovação é guiada pela habilidade de ver conexões, oportunidades pontuais e tirar vantagem delas (TIDD et al., 1997).

O desenvolvimento de novas tecnologias e novos produtos, até então, era feito no setor de $\mathrm{P} \& \mathrm{D}$ (pesquisa e desenvolvimento) interno das empresas. Esta era também uma estratégia para barrar a entrada de concorrentes no mercado. Chesbrough (2006) chama de closed innovation (inovação fechada) este modelo antigo, onde as empresas entendem que para uma inovação de sucesso é necessário gerar as ideias internamente, desenvolvê-las, colocá-las no mercado, distribuir etc. Além do aumento do número de pessoas qualificadas e mobilidade das mesmas, dificultando as empresas de controlar as expertises, nos dias de hoje, empresas 
líderes do mercado tem se deparado com grande concorrência de iniciantes que, extraordinariamente, tem pouca pesquisa básica (CHESBROUGH, 2006). Tidd (2006) afirma que a competição estimula a empresa a investir em inovação e mudanças já que os competidores ameaçarão a existência da empresa se elas não o fizerem. Além disso, estudiosos de inovação tem entendido que desde os anos 1970 as fontes inovativas vem, comumente, de fora das firmas (WEST et al. 2014).

Surge, então, uma prática na gestão da inovação que chamamos de "inovação aberta", onde se é aproveitado todo tipo de intervenção e fonte criativa advinda de todos os atores internos ou externos do ambiente em que a empresa se insere (stakeholders, universidades etc). Para Chesbrough (2006), a inovação aberta (open innovation) é o resultado da ação conjunta destas fontes, resultando em uma rede que se beneficia de forma cabal. Em outras palavras, inovação aberta é 'o uso intencional de entrada e saída de conhecimento a fim de acelerar a inovação interna e expandir os mercados para uso externo da inovação, respectivamente' (CHESBROUGH et al., 2006; GASSMAN et al., 2010). A expressão propriedade intelectual pode, aqui, ser substituída por parceria intelectual.

Esta nova abordagem cria laços maiores entre universidades-empresas, universidadesuniversidades e empresas-empresas. Isto implica um uso extenso de relações interorganizacionais para internalizar ideias externas e vice-versa, estabelecendo relações com vários parceiros, em particular universidades (CHIARONI, 2011 ). Appleyard e Chesbrough (2017) chamam de open-open innovation os projetos que se desenvolvem de maneira aberta e geram produtos sem propriedade intelectual. Este artigo relata um caso que se encaixa perfeitamente nesta abordagem de open-open innovation.

Ao que concerne o desenvolvimento de produtos para a área da saúde, encontramos uma situação complexa devido à rigidez das normatizações relacionadas à utilização de equipamentos de saúde e os longos períodos para implementação de inovações. Esta área, muitas vezes carente de inovações, encontra hoje novas oportunidades e abordagens que podem mudar a situação de pessoas no mundo todo. As práticas de inovação aberta, por exemplo, na área médica, tem grande destaque ao que concerne as pesquisas de doenças raras (BULLINGER et al., 2012). São nessas áreas que o conhecimento é limitado e disperso localmente, o que torna a inovação aberta mais importante ainda. Segundo Bullinger et al. (2012), a integração do público na pesquisa e desenvolvimento na área de cuidados da saúde é essencial para a inovação avançada. Esta participação de pacientes e membros do público tem potencial de promover melhorias não somente na qualidade dos produtos mas também na relevância e impacto da pesquisa e desenvolvimento pois eles podem trazer conhecimentos importantes e insights de experiências para a pesquisa. É também somando parcerias com universidades que a área de desenvolvimento de produtos voltados à saúde encontra hoje soluções.

Este artigo tem como objetivo apresentar uma experiência de desenvolvimento de produtos da área de saúde no contexto acadêmico, por meio de um processo de inovação aberta centrado no trabalho compartilhado por duas Universidades, uma no Brasil e outra no Reino Unido, onde a entrada e saída de conhecimento são primordiais para a efetivação da inovação.

A pesquisa busca demonstrar a viabilidade da inovação aberta a partir do trabalho cooperativo entre pesquisadores, baseado em tecnologias abertas e voltada para o desenvolvimento de soluções adequadas (mas não restritas) à população de baixo poder aquisitivo, desenvolvendose por meio de práticas de inovação aberta em conjunto com o fablab de uma universidade corporativa ligada a uma empresa metal mecânica privada.

O projeto se desenvolve a partir de um cenário mundial onde os problemas de audição afetam cerca de 360 milhões de indivíduos, dos quais 32 milhões são crianças, segundo dados da 
OMS de 2017. A agência da ONU também mensurou que dificuldades de comunicação, isolamento social e estigma associados às dificuldades de audição geram prejuízos de U\$573 bilhões. Para dar educação adequada às crianças são necessários U\$3,6 bilhões adicionais em investimentos no ensino, além disso, tratamentos como o uso do aparelho auditivo também devem ser adotados para melhorar a qualidade de vida deste público. O acesso a estes aparelhos, sobretudo em países subdesenvolvidos, é limitado, principalmente, por questões financeiras. Assim, um grupo de pesquisa de Tratamentos de Sinais Biomédicos de uma Universidade inglesa desenvolve um projeto que visa melhorar e ampliar este acesso. Focados em aprimorar as funções a baixo custo, eles desenvolveram o sistema a partir do dispositivo Raspberry Pi (figura 1) que custa menos de 50 dólares. O Raspberry Pi é um microcomputador desenvolvido no Reino Unido pela Fundação Raspberry Pi, onde todo o hardware é integrado em uma placa única a fim de promover o ensino e possibilitar às pessoas de todas as idades a estudar e programar em linguagem simples mas de alto nível. Ao que concerne a interface produto-usuário, procurou-se uma parceria com uma Universidade brasileira. O projeto baseia-se na construção de uma plataforma aberta, onde projetistas de todo o mundo possam acessar, modificar e melhorar o produto e, principalmente, atender demandas locais negligenciadas.

Figura 1. Raspberry Pi. Fonte: Autores (2017)

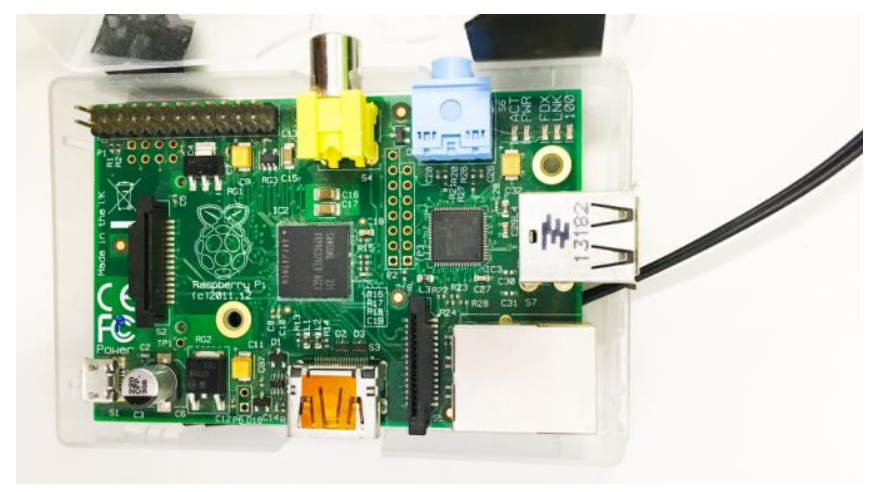

\section{METODOLOGIA}

O projeto inicia-se com uma demanda de uma Universidade do Reino Unido que, através de um grupo de pesquisa de Tratamento de Sinais Biomédicos, desenvolve tecnologia compatível aos aparelhos auditivos por meio de um microcomputador de baixo custo. Entretanto, para a implementação e uso deste recurso pelos potenciais usuários, os alunos não tem as competências necessárias para desenvolvimento do produto que contenha o sistema por eles desenvolvido e procuraram uma parceria com um grupo de pesquisa e professor do departamento de engenharia de produção de uma Universidade brasileira. Em sua fase final, o projeto será executado em um fablab de uma universidade corporativa ligada a uma empresa metal mecânica privada que é parceira da Universidade brasileira.

No Brasil, valores de um aparelho auditivo varia entre dois mil a seis mil reais. Sua aquisição é primordial para estabelecer qualidade de vida do deficiente auditivo. Para este projeto, estima-se a realização de um produto de valor de custo de até dez vezes menor que um aparelho auditivo convencional.

Após o projeto do sistema, a interface usuário a ser produzida será composta, principalmente por uma case que contenha o microcomputador e bateria e um plug com saída de áudio que se conecte à orelha. Para tal, por meio de uma disciplina de Projeto do Produto, cursada por 
alunos de graduação em engenharia de produção e em design, o tema foi proposto. O trabalho dos alunos foi acompanhado pelo professor da disciplina e por um Designer, atualmente cursando o Mestrado Profissional em Inovação Tecnológica e Propriedade Intelectual na Universidade.

\subsection{Divisão temáticas centrais e transversais}

A turma conta com cerca de 50 alunos, em sua maioria graduandos em engenharia de produção. Os alunos foram divididos em nove temas centrais baseados na escolha do públicoalvo a ser trabalhado no desenvolvimento do produto. Os grupos-alvo se dividem em cinco faixas etárias e em cada existe o foco no "público geral" ou o foco em "público de baixa renda". Sendo assim, os grupos principais são formados por cinco integrantes distribuídos entre os temas: Crianças; Crianças II (baixa renda); Adolescentes; Adolescentes II (baixa renda); Jovens Adultos; Jovens Adultos II (baixa renda); Adultos de Meia-Idade; Adultos de Meia-idade II (baixa renda); Idosos. Devido à quantidade de alunos matriculados na disciplina, houve a formação de somente um grupo principal que dirigiria os estudos voltados ao público idoso em geral. Os alunos classificaram como crianças, os indivíduos de até 11 anos; como adolescentes, os indivíduos de até 18 anos; como jovens adultos, os indivíduos de até 29 anos; como adultos de meia-idade, os indivíduos de até 59 anos e idosos, aqueles acima de 60 anos, de acordo com definições do Estatuto da Criança e Adolescente e Estatuto do Idoso (2017). A definição de faixas de renda foram feitas de acordo com o Portal Brasil de Cidadania e Justiça do governo nacional (2017), onde famílias de baixa renda são caracterizadas como famílias com renda mensal de até meio salário mínimo por pessoa ( $\mathrm{R} \$ 468,5$ em 2017) ou com renda familiar total de até três salários mínimos ( $\mathrm{R} \$ 2.811$ em 2017).

Os grupos temáticos foram definidos e, assim, foi necessário estabelecer funções aos seus integrantes de maneira que cada um tenha um papel fundamental no desenvolvimento do projeto. Para isto, criaram-se cinco grupos transversais que tratariam de temas comuns a todos os projetos principais. Estes grupos transversais seriam compostos por quatro ou cinco integrantes e deveriam conter alunos de temáticas centrais diversas. Os temas transversais traçados são: Usuários; Mercado; Patentes; Tecnologia RaspberryPi; Prototipagem. Assim, na temática central "Crianças", por exemplo, cada um dos cinco integrantes trabalha em um grupo transversal diferente para trazer o conhecimento complementar para o progresso do projeto, estudado transversalmente com participantes de outras temáticas centrais.

Tabela 1. Organização grupos transversais e temas. Fonte: Autores (2017)

\begin{tabular}{|c|c|c|c|c|c|c|c|c|c|}
\hline & Crianças & Crianças II & Adolescentes & Adolescentes II & Jovens & Jovens ॥ & Adultos & Adultos II & Idosos \\
\hline Grupo Transversal - Usuários & Integrante A & Integrante B & Integrante B & Integrante A & Integrante A & Integrante B & Integrante B & Integrante A & tegrante $\mathrm{A}$ \\
\hline Grupo Transversal - Estudo de Mercado & Integrante A & Integrante B & Integrante B & Integrante A & Integrante A & Integrante B & Integrante B & Integrante A & Integrante B \\
\hline Grupo Transversal - Estudo de Patentes & Integrante A & Integrante B & Integrante B & Integrante A & Integrante A & Integrante B & Integrante B & Integrante A & Integrante $\mathrm{A}$ \\
\hline Grupo Transversal - Tecnologia RPi & Integrante A & Integrante B & Integrante B & Integrante A & Integrante A & Integrante B & Integrante B & Integrante A & Integrante B \\
\hline Grupo Transversal - Prototipagem & Integrante A & Integrante B & Integrante B & Integrante A & Integrante A & Integrante B & Integrante B & Integrante A & Integrante A \\
\hline
\end{tabular}

Os alunos realizaram as atividades de pesquisa e debate em grupos transversais A e B, em uma divisão que visava proporcionar maior diversidade de temas centrais em um mesmo grupo (tabela 1). O grupo transversal intitulado "Usuários" foi responsável por toda a pesquisa envolvendo os diversos públicos, identificação do problema, perfil dos usuários, realização de entrevistas e surveys. Já o grupo transversal "Mercado" foi responsável pela análise do mercado, concorrentes e tendências emergentes. O grupo "Patentes" fez uma pesquisa e 
análise de patentes depositadas no Brasil e no mundo. O grupo "Tecnologia Raspberry Pi" cuidou do intermédio entre os grupos de pesquisa da Universidade inglesa e da Universidade brasileira. Este grupo estudou e transmitiu os conhecimentos necessários para se projetar a partir do sistema desenvolvido. Por fim, o grupo "Prototipagem" levantou as soluções existentes em termos de produção e prototipagem mais adequadas à realidade do projeto.

\subsection{Resultados grupos transversais}

Após seis semanas de pesquisas de campo, reuniões e sessões de orientação semanais com o professor e o mestrando, os grupos transversais A e B apresentaram em um seminário os resultados abrangentes dos públicos diversos para essa primeira etapa de imersão e conceituação do produto.

Além dos seminários, cada grupo transversal redigiu um relatório a fim de documentar passo a passo as pesquisas e resultados, que foram disponibilizados em uma plataforma digital da Universidade referente à disciplina com acesso livre para toda a turma. O fato de que estas informações foram disponíveis para os alunos é fator relevante para que os trabalhos centrais sejam desenvolvidos de forma concisa e embasada, a partir da proposta de disseminação da informação levantada por todos os grupos transversais.

Ao final, cada grupo principal tem um membro que participou de um grupo transversal diferente, fazendo com que cada integrante tenha papel relevante e especialidade complementar no processo.

Os grupos transversais se encerram assim, definitivamente, e os alunos levam os conhecimentos obtidos aos times de origem.

\subsection{Grupos de origem}

As competências angariadas servirão para essa próxima etapa de desenvolvimento e ideação do produto. Os estudantes retornam aos grupos de origem para, em seguida, traçar os requisitos de projeto. Uma apresentação foi incluída no cronograma para que os grupos (de origem) destacassem e comentassem as contribuições e perspectivas identificadas nas pesquisas transversais que influenciarão nas decisões projetuais relativas a cada tipo de usuário. Esta apresentação foi extremamente rica para entender o êxito da etapa anterior.

A partir destes resultados (figura 2), foram realizados exercícios para (1) geração de alternativas formais para os produtos e (2) adequação ergonômica das soluções desenvolvidas. Este ciclo ocupou aproximadamente três semanas do curso. Após dinâmicas de representação e geração de alternativas, os grupos debateram e escolheram as soluções projetuais julgadas mais eficientes e adequadas a serem executadas. Para tal, foi proposta uma exposição de sketches, croquis e representações das gerações de alternativas de cada grupo. 
Figura 2. Amostra de sketches alternativas. Fonte: Autores (2017)

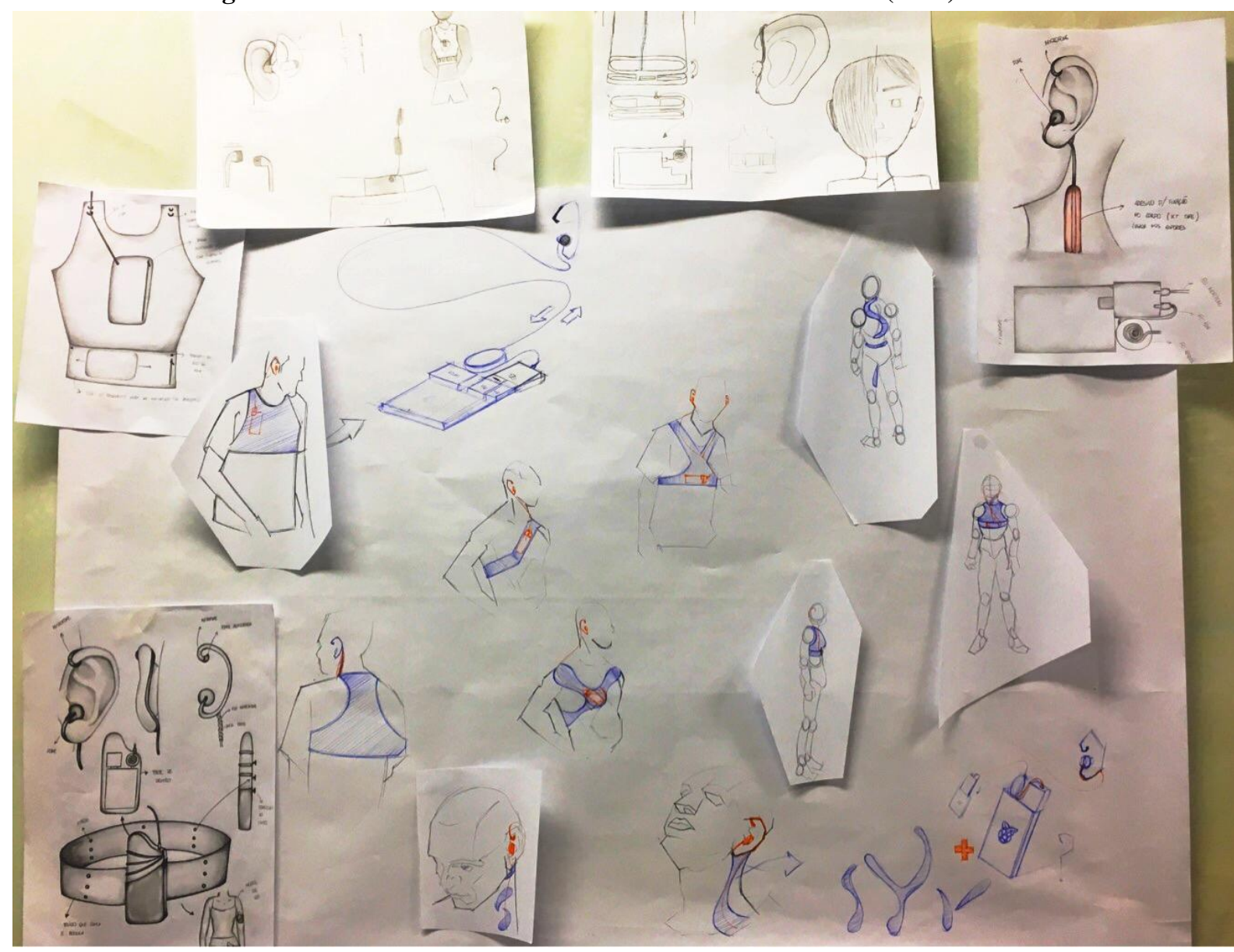

Os alunos expuseram as ideias de seus grupos e foram incentivados a colaborar com os outros grupos através de anotações em post-its ou comentários e sugestões. Este momento de troca foi de grande relevância para que as equipes assinalassem pontos negligenciados e oportunidades não identificadas anteriormente.

Figura 3. Amostra de protótipos iniciais de alternativas. Fonte: Autores (2017)

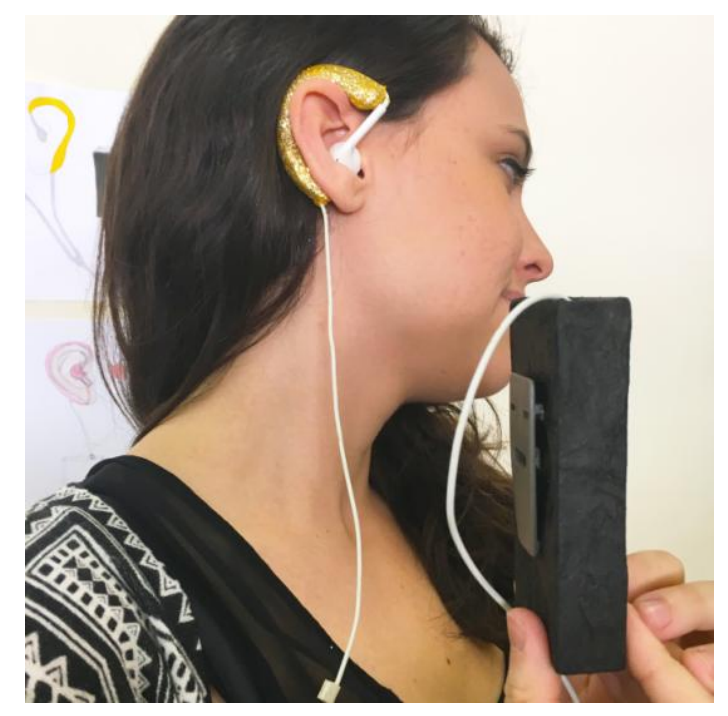


As alternativas desenvolvidas e selecionadas pelos grupos foram prototipadas e apresentadas aos colegas em uma sessão de apresentação do projeto, para que os alunos testem aspectos que vão além da representação gráfica. Os protótipos proporcionaram a constatação da necessidade de melhoria em aspectos funcionais e de usabilidade nas alternativas selecionadas. A ideia neste caso é a prototipação a partir de materiais simples (figuras 3 e 4), como argila, papel, "biscuit", poliuretano expandido etc.

A sessão de apresentação é organizada como uma "feira de projetos", onde cada grupo deve circular entre os demais, de forma que haja troca de ideias e experiências. É enfatizada a ideia de que a crítica é positiva, no sentido de contribuir para a melhoria dos resultados da turma. $\mathrm{O}$ objetivo formal apresentado é que o resultado da turma como um todo grupo importa mais do que resultados individuais ou da existência de "grupos de excelência". O objetivo é reduzir o caráter competitivo observado em turmas anteriores da disciplina.

Figura 4. Amostra de protótipos iniciais de alternativas. Fonte: Autores (2017)

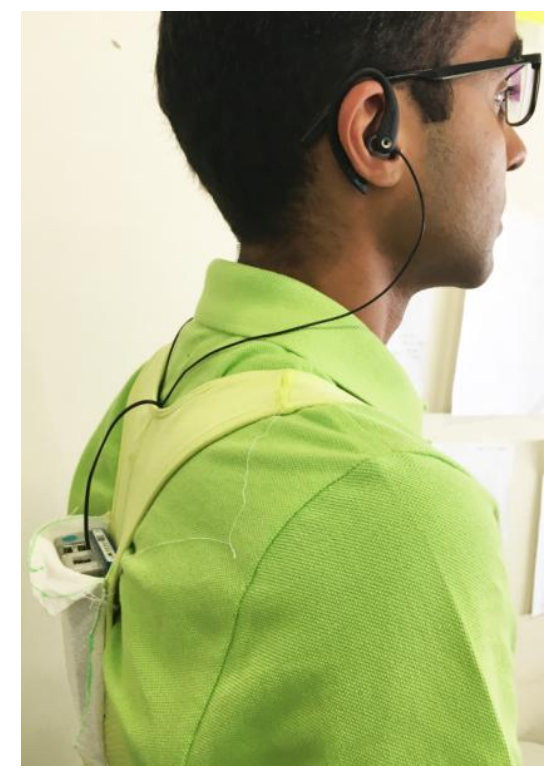

\subsection{Próximas Etapas do projeto}

A partir dos resultados obtidos nesta etapa é realizado um exercício de análise de valor (CSILLAG, 1995) em sua etapa de execução, onde os alunos refinam as soluções adotadas e as descrições técnicas do produto proposta. Eles apresentarão ainda a definição dos materiais, processos de fabricação do produto e um mock-up funcional a ser prototipado no fablab de uma universidade corporativa ligada a uma empresa metal mecânica privada.

Após os resultados do projeto desenvolvido pela disciplina serem apresentados, o grupo de pesquisa da Universidade brasileira exercerá papel de intermediador com a Universidade inglesa e ambos deverão executar a fase final do projeto que consiste na construção de uma plataforma aberta onde pesquisadores do mundo todo possam acessar, modificar e melhorar o produto e, principalmente, atender demandas locais negligenciadas. Ademais, encontrou-se na cultura fablab, um meio para difundir o projeto e permitir que projetistas possam prototipar o produto a baixo custo. Para tanto, de acordo com os princípios do fablab, o projeto estaria dentro de uma rede de contatos, que disseminam as informações internacionalmente. Este ponto foi identificado em reunião com o fablab da universidade corporativa parceira e se encaixa perfeitamente no escopo da proposta. 


\section{RESULTADOS E DISCUSSÃO}

A colaboração entre universidades com competências diferentes podem, além trazer resultados significantes para a inovação e aplicações para a sociedade como um todo, ser força motriz para motivar alunos que estão imersos em longos períodos de ensino tradicional mas são, paradoxalmente, cobrados por soluções inovadoras e criativas.

As plataformas escolhidas para gerenciamento do projeto foram o sistema online da própria Universidade brasileira, apoiando-se em ferramentas de compartilhamento de arquivos em nuvem. A comunicação se deu por meio de emails e conversas via skype, intermediadas por alunos e professores, além de uma visita, ao Brasil, do professor responsável pelo projeto na Inglaterra.

As dinâmicas envolvendo cooperação entre grupos de uma mesma disciplina também traz resultados surpreendentes na descoberta de que pessoas que tem competências e vivências diferentes podem trazer abordagens e soluções projetuais que o grupo não conseguiu identificar. A chamada exposição de geração de alternativas, neste artigo, conduziu discussões e à descoberta de pontos relevantes até então negligenciados. Esta troca incutiu em melhoria nas soluções adotadas por cada grupo e refletirá em resultado positivo para o produto final.

A formação dos grupos transversais foi relevante também na didática de evitar que alguns alunos conduzam todo o projeto enquanto outros não se envolvam de maneira substancial. Cada aluno tendo um papel em seu grupo induz à cooperação e envolvimento de todos os estudantes para que o projeto principal não fique defasado. Indubitavelmente, há ainda aqueles que não se comprometem de maneira aprofundada mas a cobrança e identificação da atribuição de cada um é clara. A disposição dos trabalhos transversais em plataforma de livre acesso à todos grupos visa minimizar os gaps e permitir que todos tenham conhecimento das pesquisas transversais $\mathrm{A}$ e $\mathrm{B}$, os pontos que possam ser abordados de maneira diferente ou até mesmo detectados por somente um grupo.

\section{CONCLUSÃO}

O papel dos intermediadores nas universidades e na disciplina é de grande importância na gestão do fluxo de conhecimento entre os atores no desenvolvimento do projeto. As plataformas escolhidas, apesar de suas limitações, cumprem o papel neste sistema simples de gestão envolvendo poucos atores. Este tipo de inovação, baseado no compartilhamento intencional do conhecimento, mostrou-se necessário ir além da difusão de ideias entre Universidades. Quando promovida a propagação de ideias dentro da sala de aula, os grupos agiram de maneira mais colaborativa e participativa. As dinâmicas e o processo pelo qual se deu o projeto permitiu maior entrosamento e convivência com o máximo de pessoas em prol de um objetivo comum. Se promovido de forma convencional, onde o grupo de cinco integrantes permanece unido ao longo do semestre, claramente não teríamos os mesmos resultados.

Para empresas, a inovação aberta pode ser uma solução para sua sobrevivência, acelerar a inovação interna e/ou conquistar novos mercados. Para as Universidades, as práticas colaborativas e desenvolvimento de tecnologias, é fonte de estímulo e preparação para a formação de profissionais mais engajados e competentes. As mudanças no ensino tradicional, sendo constantemente colocado em pauta, asseguram também a sobrevivência da Universidade e seu papel em formar cidadãos que pensam, criticam e são criativos. 


\section{REFERÊNCIAS}

APPLEYARD, Melissa M.; CHESBROUGH, Henry W. The dynamics of open strategy: from adoption to reversion. Long Range Planning, v. 50, n. 3, p. 310-321, 2017.

BULLINGER, A.; et.al. Open innovation in health care: Analysis of an open health platform. Health policy, 2012.

CHESBROUGH, H. W. The era of open innovation. Managing innovation and change. 2006.

CHIARONI, D.; et.al. The open innovation journey: how firms dynamically implement the emerging innovation management paradigm. Technovation, 2011.

CSILLAG, J. M. Análise de valor. São Paulo: Editora Atlas, 1995.

GASSMAN, O.; et.al. The future of open innovation. R\&D Management, 2010.

ONU. OMS: 1,1 bilhão de pessoas podem ter perdas auditivas porque escutam música alta. Disponível em <http://nacoesunidas.org/oms-11-bilhao-de-pessoas-podem-ter-perdasauditivas-porque-escutam-musica-alta/>; Acesso em 05/06/2017.

ROSSI, A. Inovar para competir. Fundação Dom Cabral - Núcleo de Inovação. Nova Lima, 2009.

TIDD, J.; et.al. Managing innovation: integrating technological, market and organizational change. Vol.4. Chichester: Wiley, 1997.

TIDD, J. A review of innovation models. Imperial College London 16, 2006.

WEST, J.; et.al. Open innovation: The next decade. 2014. 